Carla Bazzanella*

\title{
The Complex Process of Mis/Understanding Spatial Deixis in Face-To-Face Interaction
}

\author{
https://doi.org/10.1515/soprag-2019-0004
}

Abstract: In general, understanding requires cognitive and linguistic skills, encompasses cultural, social, contextual and individual aspects, and is characterised by gradualness and dynamicity.

In this study, the intertwined set of relevant components involved in the complex process of understanding space deixis will be analysed in the specific context of face-to-face interaction. In everyday conversation, this process is unavoidably mutual and may include misunderstanding (which often opens up a way to understanding), repairs, reformulations and negotiation cycles, all of which eventually lead to understanding and mutual comprehension or to communication failure. Many scholars have already pointed out several elements that influence interactants' understanding in a positive or negative way: on the one hand, shared physical context, cotext, common ground, shared knowledge and avoidance devices; on the other, ambiguity, speakers' failures, and interactants' asymmetric features with regard to language and culture. The interactional context, the cotext and the use of multimodal resources (resorted to as co-speech or to substitute language) play a significant role in the dynamic process of understanding spatial deixis, often helping to overcome the difficulties related to peripheral cases of spatial deictics and other causes of misunderstandings, which can either work as a starting point for understanding or lead to communication failure.

Keywords: spatial deictics, understanding, context, face-to-face interaction, multimodality

\section{An introduction to mis/understanding}

\subsection{A complex process}

Analysing the understanding and misunderstanding of spatial deixis in the specific context of face-to-face interaction involves several multifarious

*Corresponding author: Carla Bazzanella, Dipartimento di Filosofia e Scienze dell’Educazione, University of Turin, v. S. Ottavio 20, Torino, TO 10124, Italy, E-mail: carla.bazzanella@unito.it

Ә Open Access. (C) 2019 Bazzanella published by De Gruyter. (cc) BY-NC-ND This work is licensed under the Creative Commons Attribution-NonCommercial-NoDerivatives 4.0 License. 
aspects that have a strong, reciprocal relation. The main goal of this paper is to clarify their connected features and highlight how the significance of their intertwinement affects the comprehension process, in the hope that the proposed framework can also have positive spill-over effects in relevant applied fields.

"Do others understand what we say or write? Do we understand them?", as Taylor (1992, p. 3) asks in a volume that underlines the frequency of mutual misunderstanding.

In fact, the complex process of understanding requires cognitive and linguistic skills, and involves several issues such as contextual cues, ${ }^{1}$ reference identification and common ground; last but not least, understanding is constrained by cultural, social and individual features.

Furthermore, understanding is characterised by gradualness. ${ }^{2}$ It cannot be considered as an all-or-none phenomenon since it can encompass different degrees of penetration (Vendler, 1994) and vary from complete comprehension to absence of understanding, passing through phases of partial misunderstanding/understanding that are not strictly contrasting.

In a way, a misunderstanding can open up the way to understanding. ${ }^{3}$ The process of "coming to an understanding" (Weigand, 1999, p. 766) includes selfcorrections and repairs (Schegloff, 1992), reformulations (e. g. Fetzer, 2007), side sequences and the negotiation cycle of misunderstanding (Bazzanella \& Damiano, 1999), and can often be solved in the course of interaction.

In cooperative interactions (the positive side of Kecskes' (2010) paradox of communication), understanding consists in a mutual and dynamic achievement that involves all the participants, who alternate (when they do not overlap) their roles of speaker and addressee at each turn and co-construct communication.

Before discussing the process of mutual understanding with regard to spatial deixis (§ 2), we analyse the different factors that can trigger misunderstanding and/or overcome them.

1 Cf., e. g. De Cock (2018) with regard to the important role of contextual cues in the interpretation of Spanish spatial deictic adverbs.

2 "Unlike the socio-cultural approach, the socio-cognitive approach emphasizes that both the actual situational experience and context, and prior experience and context, are important in meaning construction and comprehension, but to varying degrees.” (Kecskes 2018, p. 21).

3 Cf. Trognon \& Batt (2018, p. 27) in an evolutional perspective: "El integrar el uso del lenguaje natural en la máquina de la interacción produjo, en el largo plazo, un sistema de comunicación más eficiente, porque no cancela la indecibilidad de la comunicación al momento de su transmisión, sino que lo maneja paso a paso, localmente.”. 


\subsection{Triggers of misunderstanding and dynamic phases of understanding}

In recent years, several scholars have studied (mis)understanding, especially in interactional settings, by focusing on various aspects: levels, sources, phases and outcomes (among many others, Zaefferer, 1977; Verdonik, 2010; Mustajoki, 2017a).

The levels at which misunderstanding and difficulties in intersubjective comprehension arise are auditory, visual, cognitive, gestural, cultural and linguistic (the latter, more specifically, involves phonic, lexical, syntactic, semantic and pragmatic aspects).

A number of causes or triggers of misunderstanding that can also cooccur in unsuccessful communication has been pointed out, such as the following ones:

- external sources such as channel disturbances, responsible for mishearing,

- the characteristic features of face-to-face interaction, that is, among others, elliptical speech and the 'micro-planning' of spoken language,

- ambiguity, ${ }^{4}$ indeterminacy and vagueness of language (Jucker, Smith, \& Lüdge, 2003; Bazzanella, 2011),

- metaphorical meaning, figurative language and non-literal meaning,

- the high frequency of implicit meaning, presuppositions/ "presumptions" (Macagno \& Bigi, 2017) and the need for conversational inferences,

- inter- and intra-linguistic varieties, as in, respectively, examples (1) above (with regard to Hungarian in comparison to English and Italian), and (2) above (with regard to the regional language spoken in Tuscany and standard Italian),

- both speaker's and interactant's "mental worlds" (Mustajoki, 2017a) and their unshared beliefs, knowledge, and competence, ${ }^{5}$

- interactants' idiosyncratic failures related to asymmetries in role/competence/culture,

- speaker's failures regarding her/his cognitive load, lack of proper recipient design, slips of the tongue and imprecision (e. g. Mustajoki, 2012),

- interlocutor/s' cognitive load, lack of attention and inappropriate inference.

4 According, e. g. to Zaefferer (1977) and Blum-Kulka \& Weizman (1988), ambiguity has been considered to play a major role in generating misunderstanding. In Bazzanella \& Damiano (1999, p. 818), semantic ambiguity results as the first trigger of misunderstanding (66\%).

5 The special issue on Focus on the speaker edited by Kecskes (2013) provides a variegated panorama of speaker's aspects, including more 'classical' perspectives and the recent sociocognitive approach. 
Another relevant, widely discussed issue regards the different kinds and frequency of misunderstanding occurring in conversations between natives (NS) or between NS and nonnatives (NNS).

At the end of the nineties, among others, Thomas (1983), among others, analysed specifically the various kinds of pragmatic cross-cultural failures (more sensitive to social criticism than grammatical errors) and underlined the importance of speaker's intention and its recognition by interactants. According to Varonis and Gass (1985), the difficulties in dialogues between NS and NNS derive from lack of common ground (that is, different world views and cultural assumptions) and from dissimilar linguistic systems.

Recently, several scholars (among others, Hinnenkamp, 2009; Kecskes, 2015; Pietikäinen, 2016; Mustajoki, 2017b) have been more inclined to underline the continuum rather than the dichotomy ${ }^{6}$ between intracultural and intercultural communication, and other factors of misunderstanding and positive aspects of intercultural exchanges have emerged. In Kecskes' words (2018):

[...] in intercultural communication, a more conscious recipient design, a more careful attention to the audience may be involved than in intracultural communication, in which interlocutors do not have to deal with language skill issues, and may rely on more spontaneous, (partly) prefabricated speech and less monitoring. (pp. 118-119). ${ }^{7}$

In the following, the theoretical background concerning (mis)understanding will be applied to the specific investigation of spatial deixis, initially by discussing briefly the relationship between space, cognition and language (§ 2.1), as well as pointing out the differences between central and peripheral spatial deictics (§ 2.2). Subsequently, we will focus on the pragmatic impact of context, interaction and multimodality, and their significant interplay in the dynamic, interactional phases of successful (or unsuccessful) understanding of spatial deixis (§ 3).

\footnotetext{
6 "[...] it would be a mistake to talk about a dichotomy. There is nothing like pure intracultural and intercultural communication. What we have is something in between on a continuum between the two ends." (Kecskes 2015, p. 172).

7 With specific regard to intracultural, informal communication, one cannot ignore the fact that a high frequency of misunderstandings in everyday life between husband and wife or between friends is usual (see, e. g. Mustajoki 2017b), as is confirmed also by our personal everyday experience.
} 


\title{
2 Space and spatial deixis
}

\subsection{An overview}

\begin{abstract}
Although [...] common-sense thinking about space since modernity has been infiltrated by the absolute notion of space, relative (orientated, perspectival) notions of space are not only what most premodern everyday spatial thinking seems to have been based on: they also continue to play an important role today in everyday practices, i. e. in our incorporated knowledge of how to orient ourselves and others in space. (Auer, 2012, p. 55)
\end{abstract}

Space plays a fundamental role in human cognitive, cultural, social and individual organisation, and many scholars within both scientific and humanistic communities have increased their research work on its manifold aspects. To quote an example, Dehaene and Brannon (2011) have highlighted the commonalities of space, time and numbers in the brain: "In the course of their evolution, humans and many other animal species have internalized basic codes and operations isomorphic to the physical and arithmetic laws that govern the interaction of objects in the external world" (pp. viii-ix).

Verbal, gestural and symbolic spatial referring, as well as other mental operations, have been characterised on the one hand by universal tendencies and, on the other, by relativistic features related to wide linguistic and cognitive diversity and grounded in a large amount of cross-cultural data (e. g. Levinson, 1996; Evans \& Levinson, 2009). Against the contraposition of universalistic and relativistic perspectives, partial integrations have been proposed in domains such as time, actions, colours, numbers and emotions. With specific regard to space in language, Talmy (2005) suggested a combination of the following two sets: at the componential level, a relatively closed inventory of fundamental spatial elements that are universally available; at the compositional level, a specific, relatively closed set of schemas for each language. ${ }^{8}$

Space is not only an abstract, theoretical notion, but a crucial dimension of everyday life and part of our everyday language. In the form of spatial deixis, it is also a useful device for orienting ourselves and placing people and objects in the world:

8 See also Auer et al. (2013), p. 2: "When studies of different aspects of language and space are arranged side by side, one can begin to see unity in the diversity that characterizes the study of language and space". Here the topic of spatial deixis will not be dealt with from the perspective of a particular language, but as a phenomenon with some degree of universality. 
Cognitive processes sometimes constitutively involve multiple loops between brain, body, and world, where 'world' includes both the physical and the social environments with which embodied brains couple, the 'scaffolding' on which they lean. (Sutton, 2004, p. 506)

Starting from the pioneering works by Bühler (1934) and Fillmore (1975), spatial deixis has been analysed in a number of linguistic research areas such as pragmatics, typology, cognitive linguistics and conversation analysis. ${ }^{9}$

Here, from a mainly pragmatic perspective, the distinction between the spatial deictic centre and peripheral cases of spatial deixis (that is, respectively, related or unrelated to Lyons' canonical situation (1977, p. 637)) (§ 2.2) will constitute the starting point for analysing the intertwinement of linguistic, contextual, multimodal and interactional components activated during the interactionally-construed process of understanding spatial deixis.

In general, cognitive, cultural, social and linguistic systems, together with context, cotext, and propositional content, strongly affect the possible comprehension of spatial deixis.

Specifically, in face-to-face interaction, multimodal resources such as gestures (particularly pointing), embodied action, gaze, and body posture all of them commonly resorted to in face-to-face interaction and used simultaneously with language or to substitute it play a significant role in everyday conversation and also in language pathologies such as aphasia (§ 3).

\subsection{The origo and forms of spatial deixis}

According to Lyons (1977, p. 367), the canonical situation includes the following prototypical features: the dyadic pair, and in general, the participants in the interaction; the spoken language; the notion of 'turn-taking' (triggering the dialogically-construed process); the shared physical context, which entails temporal synchrony (here is also now). This communicative configuration is grounded in the origo, that is, in the deictic centre of a coordinate system involving three dimensions: ego, hic and nunc ('I', 'here' and 'now'), where the speaker at the time of utterance serves as a referent and deictic anchorage for personal, spatial and temporal orientation (Bühler, 1934). The three orientations, organised in an egotic way (Levinson, 1983, p. 63), typically characterise the central case of deixis.

9 Necessarily, the vast range of studies in historical linguistics, psycholinguistics and neurolinguistics, and in cognate disciplines such as philosophy, anthropology, sociology and cognitive neuroscience will not be dealt here. 
The egocentricity of the deictic centre has been criticised, among others, by Hanks (1990): “In assuming egocentricity in deixis, one runs the risk of mistaking a part or the whole, overlooking several basic facts: interaction puts in play the reciprocity of perspectives, the production of mutual knowledge, conflict and asymmetry" (p. 7).

A dialogic approach, taking into account the several components involved in the ongoing communicative event, has prevailed in recent years. Instead of strongly contrasting the two kinds of perspectives, the origo has been integrated into a wider perspective. To mention an example, Fricke (2002), who takes co-speech and gestures into account, differentiates between the primary origo, connected to the role of the speaker/addressee, and the secondary origo, which can be shifted, "starting from the positioning of the speaker and her hearer(s)” (Gómez Sánchez \& Jungbluth, 2015, p. 245) to several entities. The spatial origo is often extended, using a deictic projection (Lyons, 1977, p. 579), from the primary one to "somebody else's point of view as a transposed vantage point” (Laczkó, 2012, p. 2919), that is, to peripheral cases of spatial deictics ("space builders" in Mihatsch's (2015, p. 472) words), where here symbolically refers to:

(a) a place, a city or a nation. In order to be understood, the reference needs shared physical context, appropriate cotext and common ground (§ 3.2),

(b) an imaginary locus, analogically transposed ("shifted" in Fricke's (2002) words) in two possible ways:

- $\quad$ to the speaker's body, what Bühler (1934) labelled deixis am phantasma ('in imagination'), when the speaker her/himself indicates the part of her/his body corresponding to another person's, such as in John broke his leg here, uttered while pointing (§ 4) to her/his own leg,

- or by suggesting a visual path, as in Levinson's (2004) example: "Imagine this room were my office. The book would be right here [pointing to the edge of my desk]" (p. 103),

(c) another person's location that serves as a reference point, as happens in reported speech (Fillmore, 1975) or in novels, e. g. "[...] in the opening line of one of Hemingway's short stories: The door of Henry's lunchroom opened and two men came in, where Henry has become the deictic origo" (Levinson, 2004, p. 103). In cases like this, the cotext is even more crucial for comprehension, as the room two men entered is referred to Henry's lunchroom reported in the immediately preceding text.

Locations can also be grounded in other systems of spatial deixis, such as intrinsic orientation (e.g. the front or back of a house or a car) and salient objects, such as the cathedral in a city. 
These peripheral forms and other ground-oriented ones (Prandi, 2015) are more strongly affected by linguistic variance in different linguistic spatial systems. To quote an example, while in Hungarian, according to Laczkó (2012, p. 292), ${ }^{10}$ the use of itt ('here' in English) is common in cases such as (1):

(1) Hu. Péter megérkezett Londonba, de itt is csak a lányára tudott gondolni. 'Peter has arrived in London, but he was only able to think of his daughter even here' (Laczkó, 2012, p. 292).

In the Italian translation, the Hungarian itt is mandatorily substituted by li 'there': 'Peter era arrivato a Londra, ma anche lì continuava a pensare solo a sua figlia'.

Even within an individual language, e. g. Italian, spatial deictics can vary (e. g. Ledgeway, 2015). To mention an example: standard Italian has a bipartite system (questo 'this', quello 'that'), while the regional language spoken in Tuscany adds codesto, which means 'what is near the addressee', as in the following invented case:

(2) Mi porgi codesto portacenere?

'Can you pass me that ashtray [which is near you]?'

Codesto is commonly used in Tuscany at any age, and is also used in the syntagm $O$ codesta? 'What is that?' with an anaphoric value, as a comment on somebody doing or saying something strange that triggers surprise or disapproval (in the latter case, it would correspond to 'What on earth is that?'. ${ }^{11}$ It appears to be used by the speaker in order to attribute the responsibility of the act/utterance to the interlocutor, thus to metaphorically 'approximate' codesto to her/him and distance it from her/himself ${ }^{12}$ ).

Peripheral cases, which are characterised by transposition as well as anaphoric and metaphorical uses, are more likely to trigger misunderstanding. In general, misunderstanding depends on a wide range of factors, and understanding spatial deixis in dialogue cannot be taken for granted.

10 More specifically, in Hungarian “[...] the item itt 'here' does not refer to the actual space where the speaker stands; rather, it takes the protagonist of the event related, Peter, as a point of departure for spatial orientation.” (Laczkó 2012, p. 292).

11 Personal communication by Elena Pistolesi.

12 Cf. Cairns (1991) with regard to [+distal] deictics metaphorically loading values in dialogic interactions. 


\section{Context, interaction, and multimodality in understanding spatial deixis}

As human beings, we always interact in a space, for all our life; the space may be natural or social, physical or mental, open or closed, wide or tight, but there is always a space around us and inside us. (Marotta, Lenci, Meini \& Rovai, 2010, p. 12)

According to an integrated notion of context (e. g. Bazzanella, 2002), while the global level of context concerns a priori components, the local level concerns the cotext and all the components relevant to -and activated in- a specific interaction; the two levels play together in the configuration and transformation of the interactional space. $^{13}$

In the course of interaction, the origo can change, involving mobility and re-orienting gaze, and also attention, as, for example, when interactants travel by car, shop together in self-service stores, participate in driving lessons or guided tours, or are “crossing the street” (e. g. De Stefani, 2018; Merlino \& Mondada, 2019):

Guided tours are publicly visible as "mobile formations" inasmuch as the participants can be seen walking from one scene of object-focused interaction to another. [...] The achievement of stationary positioning and the constitution of a new focus of interaction are collectively organized: the "wholeness" of the group is accomplished not only by the "guide" - who has the right and obligation to initiate a collective stand-still- but also by the "guided," who display their right to orient to the newly emerging focus of attention. (De Stefani \& Mondada, 2014, p. 173).

Furthermore, in everyday conversations the depth of understanding can also vary according to elements such as the discourse topic, the participants' specific competence, clarity of propositional content, possible avoidance devices and pre-emptive strategies (e. g. Trillo, 2011; Pietikäinen, 2016; Kaur, 2017).

The lack of common physical context, such as in telephone calls (as well as in written, partially synchronic interactions such as chat and text messages), sometimes makes understanding a laborious or even unsuccessful process. With particular regard to spatial deixis, person-oriented deictics ought to be specified when using cordless and mobile phones, which tend to delocalise speakers. For example, I'm here - uttered on a train while using a mobile phone- is completely inadequate pragmatically, given that the interlocutor cannot guess the

13 Recent studies on urban space and interaction, with specific regard to mobility, language and multimodal resources, have highlighted the significant coordination between contextual elements and the agents that are involved (Haddington, Mondada \& Nevile 2013). 
speaker's (unshared) position. The preceding utterance is usually followed by either the speaker's auto-correction/repair ${ }^{14}$ (e. g. Schegloff, Jefferson \& Sacks, 1977) or by the interlocutor's question, where?, in order to get the relevant information.

On the contrary, shared physical context and multimodal resources favour understanding as a co-construed and monitored process that often encompasses transient phases. In subsequent turns, interactants can interrogate, specify, repair and negotiate, and after one or more negotiation cycles (see fragment 3 below), can often overcome the risks of miscommunication and achieve mutual understanding.

Let us quote an example of a particularly prolonged negotiation cycle that occurred between the author (speaker A, the owner of the house), and a painter (speaker B). Speaker A tries to describe the location of a mark to speaker B, who satisfies A's request to remove it only after an intricate combination of gestures, body orientation, repairs, repetitions and specifications:

(3) A. [indicando in alto, sopra la testa del parlante B]

Scusi, può togliermi quella macchia?

B. Dov'è la macchia?

A. [indicando di nuovo in alto, sopra la testa del parlante B] In alto, in centro, nell'incrocio tra soffitto e parete.

[il parlante B si sposta a destra]

A. [indicando il centro della parete]

No, in centro.

[il parlante B si sposta, si ferma in centro e guarda in su]

A. [indicando di nuovo sopra la testa del parlante B ]

Proprio sulla sua testa.

B. [guardando un po' in su] Non la vedo.

A. [ancora indicando lo stesso punto] Più in alto, proprio dove parete e soffitto si incontrano.

B. [guardando nella direzione giusta] Ah sì, l'ho vista. La tolgo subito.

'A. [pointing up, above speaker B's head]

Excuse me, could you remove that mark?

B. Where is the mark?

A. [pointing up again above speaker B's head]

14 Cf. Dingemanse et al. (2015) for a recent and interesting study on other-initiated repairs that highlight "[...] both the basic properties of the system and the principles of its use. Both are loci for potential cultural and linguistic variation” (p. 4). 
Up there, in the middle, where the wall and ceiling meet.

[speaker B moves toward the right]

A. [pointing to the middle of the wall]

No, in the middle.

[speaker B moves, stops in the middle, and looks up]

A. [pointing again above speaker B's head]

Right above your head.

A. [looking up a bit]

I can't see it.

A. [still pointing to the same area]

Higher, right where the wall and ceiling meet.

B. [looking in the right direction]

Ah yes, I can see it. I'll remove it at once.'

If we consider misunderstanding in conversation as a possible path to the process of understanding, it should be distinguished from miscommunication -an umbrella term related to several negative meanings, including also "breakdowns, misunderstandings, struggles, and language-based aggression” (Kecskes, 2010, p. 52). ${ }^{15}$

In analysing contextual components of successful exchanges (the positive side of Kecskes' (2010) paradox of communication), the relevant individual features of all the participants in a communicative event, their common ground and the interaction itself are significant:

[...] it is the participants' knowledge systems, whether construed at a local or more global level of deliberation, that constitute reference points for the successful interpretation of simple and syntactically complex, grounded expressions. It is the shared responsibility of the discourse participants to provide and/or identify anchors that allow the respective positioning of such expressions with respect to some negotiable frame of knowledge. (Brisard, 2002, p. xiii)

Participants' characteristics -including sociolinguistic features, knowledge and beliefs, intentions and emotions- affect the speech event, which is physically, socio-culturally and interactionally grounded (e.g. Kecskes \& Zhang 2009).

Importantly, in face-to-face interaction, shared physical context, as well as participants' mutual orientation and mutual attention, allow a powerful set of multimodal resources to be exploited, i. e. gestures such as body and

15 These topics regarding miscommunication, as well as lying and verbally deceiving are not dealt with here, even though they are regrettably more and more widespread in both private and public discourses. 
head movements, facial expressions, gaze, pointing, ${ }^{16}$ embodied actions and the handling of objects actualised by participants (e. g. Müller, Cienki, Fricke, Ladewig, McNeill \& Teßendorf, 2013). All these practices help to conceptualize space, stimulate a shared focus of attention, simplify verbal expression, substitute a word or phrase for a gesture (e.g. as an answer to a question such as "Where is my umbrella?", when the umbrella is in a location nearby) and foster the understanding of spatial deixis and dialogic development. Gestural deixis is also commonly used in order to identify objects without naming them, as in:

(4) A. che cosa sono questi?

B. questi sono per me.

'A. what are these?

[stops walking, extracts product from shopping trolley]

B. these are for me (De Stefani, 2014, p. 285).

Pointing in the intended direction and actions involving mobility and touching (e.g. in deixis am phantasma, see § 2.2) are frequent in direction-giving, which often includes a parallel, verbal description (e.g. on the left, on the right, straight on).

Speaker and participants' gestures may be crucial to mutual comprehension, also in the case of a mismatch between verbal and gestural information. To quote an example, in (5), the driving instructor gives contradictory information: with his hand he points to the left, while orally announcing a turn to the right:

(5) allora più avanti ci sarà una preselezione. noi [indica a sinistra con la mano sinistra] prenderemo quella verso destra.

'now further on there will be a lane marking. we [points to the left with his left hand] will take the one to the right' (De Stefani \& Gazin, 2014, p. 69; simplified transcription).

The contradiction is not treated as problematic by the learner, who correctly turns left at the next intersection while saying $O K$, followed by the instructor's $O K$.

16 In Gesture Studies, pointing, traditionally considered as a deictic and referential device, has only relatively recently been analysed as part of other embodied actions (Kita 2003). More broadly, in an interactional perspective, pointing is considered as a situated practice, that is, as an instrument for structuring the interactants' participation and turn transition, and for creating joint attention and comprehension (e. g. Klippi 2015). 
According to the different contexts, people and activities involved, diverse degrees of precision may be implicated in gestural spatial deixis and consequently (mis)understood by the interlocutor/s. To quote an example of co-speech where the combination of verbal expression and gesture is essential for comprehension, the request in (6) will differ with regard to the more or less precise deictic here, depending on whether a surgeon or a crane operator utters it:

\section{(6) Place it here (Levinson, 1983, p. 80).}

There are three specific domains where the complete or partial recourse to multimodal devices is crucial: sign language, children's acquisition of language and speech and language pathologies. Regarding the last one, let us briefly refer to aphasia, characterised by the partial or complete loss of linguistic competence -particularly the ability to name things - but not of cognitive and pragmatic skills.

In familiar and therapeutic dialogues, aphasic persons can resort to an array of multimodal resources (for instance, by pointing to an object instead of verbalising it, e. g. Klippi, 2015) and, with the interactant's supportive help, often (but not always, e. g. Auer \& Bauer, 2011) succeed in overcoming their linguistic difficulties, taking the turn, participating in the interaction and making themselves understood (Goodwin, 1995, 2004; Merlino, 2018). By referring indexically (often by pointing; see Klippi, 2015) to features of the context and interactional space, as well as to cotext and previous turns, the aphasic speaker can indeed communicate meaning, despite her/his linguistic inabilities. Several conditions facilitate or hinder the communication and interactional participation of an aphasic person: among them, the grade of pathology, the shared or unshared physical context and the degree of common ground (e.g. high in family conversations; Klippi, 2015). In therapeutic settings, institutionally dedicated to rehabilitation, where everyday practices are reinforced by protocols and structured observations, common ground is mainly established in the interaction itself. Importantly, the interactants involved in the complicated process of verbal communication with an aphasic person succeed in co-constructing meaning also thanks to their personal cooperation, patience, creativity, ${ }^{17}$ inferential effort, use of scaffolding mechanisms similar to those used with children and attention to the various verbal and non-verbal resources (especially pointing and visual cueing devices; Klippi, 2015; Merlino, 2018) activated in the sequential organization.

17 Cf., e. g. Goodwin (1995), who reports an exemplary case and highlights how “[...] one key component of context, sequential organization, makes it possible for someone with severe aphasia to engage in meaningful conversations with others" (p. 26). 


\section{Concluding remarks}

The complex process of understanding is strongly constrained by an intertwined set of linguistic, cognitive, contextual, cultural, social, individual and multimodal aspects, activated in the configuration and subsequent dynamic transformations of a specific interaction: on the one hand, human conceptual structure, general principles of cognitive organisation, the specific linguistic system and its embodiment in human experience, and, on the other, the importance of context, the frequent use of multimodal resources and interactional participants' work greatly affect the process of understanding spatial deixis.

As we have maintained above, spatial deictic expressions related to the primary origo are generally understood in face-to-face interaction, while other forms of transposed origo may be more difficult to understand. In peripheral cases of spatial deixis, misunderstanding is often overcome by the converging actions of context, cotext, multimodal resources, avoidance strategies that may be activated and clarifying negotiation phases.

Although one can say that the general cognitive mechanisms of understanding spatial deixis are universal to a certain degree, all occurrences of (mis)understanding in interactive situations have their own story and conversational development, contingent on two kinds of sources: on the one hand, on the context and cotext, goal of interaction, propositional content, participants' features, mental models and shared (or not completely shared) language; on the other hand, the specific conceptualisation of the spatial deixis and lexicalisation of the interactants.

In the interaction itself, thanks to continuous verbal and non-verbal (that is, visual and gestural) feedback, misunderstanding can develop into understanding if grounded in a cooperative dialogic attitude between participants.

Acknowledgements: I am thankful to Susan Eerdmans for checking the English, and to Sara Merlino for discussing preceding versions of this paper.

\section{References}

Auer, P. (2012). Spatial indexicalities and spatial pragmatics. In M. Meeuwis \& J.-0. Östman (Eds.), Pragmaticizing Understanding: Studies for Jef Verschueren (pp. 53-76). Amsterdam: Benjamins. https://doi.org/10.1075/z.170.04aue

Auer, P. \& Bauer, A. (2011). Multimodality in aphasic conversation: Why gestures sometimes do not help. Journal of Interactional Research in Communication Disorders, 2, 232-259. DOI: 10.1558/jircd.v2i2.215 
Auer, P., Hilpert, M., Stukenbrock, A., \& B. Szmrecsanyi (Eds.). (2013). Space in Language and Linguistics. Geographical, Interactional, and Cognitive Perspectives. Berlin: De Gruyter.

Bazzanella, C. (2002). The significance of context in comprehension. The 'we case'. Special issue on Context in context, FOS (Foundations of science), 7, 239-254.

Bazzanella, C. (2011). Indeterminacy in dialogue. Language and Dialogue 1(1), 21-43. https://doi.org/10.1075/ld.1.1.04baz

Bazzanella, C. \& Damiano, R. (1999). The Interactional Handling of Misunderstanding in Everyday Conversations. Special issue on. Misunderstanding, Journal of Pragmatics, 31(6), 817-836.

Blum-Kulka, S. \& Weizman, E. (1988). The inevitability of misunderstandings: Discourse ambiguities. Text - Interdisciplinary Journal for the Study of Discourse 8(3), 219-241. https://doi.org/10.1515/text.1.1988.8.3.219

Brisard, F. (2002). Introduction: The epistemic basis of deixis and reference. In F. Brisard (Ed.), Grounding: The Epistemic Footing of Deixis and Reference (xi-xxxiv). Berlin: Mouton.

Bühler, K. (1934). Sprachtheorie: die Darstellungsfunktion der Sprache. Jena: Gustav Fischer.

Cairns, B. (1991). Spatial Deixis. The Use of Spatial Co-ordinates in Spoken Language. Lund University, Department of Linguistics, Working Papers, 38, 19-28. Retrieved from http://citeseerx.ist.psu.edu/viewdoc/download?doi=10.1.1.874.2564\&rep=rep1\&type=pdf

De Cock, B. (2018). Spanish spatial deictic adverbs: interpretation and discourse functioning with depersonalizing constructions. Quaderns de Filologia. Estudis Lingüístics, Vol. XXIII, 59-79. https://doi.org/10.7203/qf.23.13520

De Stefani, E. (2014). Establishing joint orientation towards commercial objects in a self-service store. How practices of categorisation matter. In Nevile, M., Haddington, P., Heinemann, T., \& M. Rauniomaa (Eds.), The sociality of objects (pp. 271-294). Amsterdam \& Philadelphia: Benjamins.

De Stefani, E. (2018). Formulating direction: Navigational instructions in driving lessons. International Journal of Applied Linguistics 28(2), 283-303. https://doi.org/10.1111/ ijal.12197

De Stefani, E. \& Gazin, A.-D. (2014). Instructional sequences in driving lessons: Mobile participants and the temporal and sequential organization of actions. Journal of Pragmatics, 65, 63-79. https://doi.org/10.1016/j.pragma.2013.08.020

De Stefani, E. \& Mondada, L. (2014). Reorganizing mobile formations: when 'guided' participants initiate reorientations in guided tours. Space \& Culture 17(2), 157-175. https://doi.org/10.1177/1206331213508504

Dehaene, S. \& Brannon, E.M. (Eds.). (2011). Space, time and number in the brain: Searching for the foundations of mathematical thought. Amsterdam: Elsevier.

Dingemanse, M., Roberts, S.G., Baranova, J., Blythe, J., Drew, P., Floyd, S., Gisladottir, R.S., Kendrick, K.H., Levinson, S.C., Manrique, E., Rossi, G., \& Enfield, N.J. (2015). Universal Principles in the Repair of Communication Problems. PLoS One 10(9), e0136100. https://doi.org/10.1371/journal.pone. 0136100

Evans, N. \& Levinson, S.C. (2009). The myth of language universals: Language diversity and its importance for cognitive science. Behavioral and Brain Sciences 32(5), 429-492. https://doi.org/10.1017/S0140525X099909X

Fetzer, A. (2007). Reformulation and common ground. In Fetzer, A. \& K. Fischer (Eds.), Lexical Markers of Common Grounds (pp. 159-179). London: Elsevier.

Fillmore, C. J. (1975). Santa Cruz Lectures on Deixis, 1971. Bloomington: Indiana University Linguistics Club. 
Fricke, E. (2002). Origo, pointing, and speech. The impact of co-speech gestures on linguistic deixis theory. Gesture 2(2), 207-226. https://doi.org/10.1075/gest.2.2.05fri

Gómez Sánchez, M. E. \& Jungbluth, K. (2015). Deixis in European Spanish. In Jungbluth, K. \& F. Da Milano (Eds.), Manual of Deixis in Romance Languages (pp. 240-257). Berlin: De Gruyter.

Goodwin, C. (1995). Co-constructing meaning in conversations with an aphasic man. Research on Language and Social Interaction 28(3), 233-260. http://dx.doi.org/10.1207/ s15327973rlsi2803_4

Goodwin, C. (2004). A competent speaker who can't speak: The social life of aphasia. Journal of Linguistic Anthropology 14(2), 151-170. https://doi.org/10.1525/jlin.2004.14.2.151

Haddington, P., Mondada, L. \& Nevile, M. (Eds.). (2013). Interaction and Mobility. Language and the Body in Motion. Berlin: De Gruyter.

Hanks, W.F. (1990). Referential practice, language and lived space among the Maya. Chicago \& London: University of Chicago Press.

Hinnenkamp, V. (2009). Intercultural Communication. In Senft, G., Östman, J.-0., \& J. Verschueren (Eds.), Culture and language use (pp. 185-200). Amsterdam/Philadelphia: John Benjamins Publishing.

Jucker, A.H., Smith, S.W., \& Lüdge, T. (2003). Interactive aspects of vagueness in conversation. Journal of Pragmatics 35(12), 1737-1769. https://doi.org/10.1016/S0378-2166(02)00188-1

Kaur, J. (2017). Ambiguity related misunderstanding and clarity enhancing practices in ELF communication. Intercultural Pragmatics 14(1), 25-47. DOI: 10.1515/ip-2017-0002

Kecskes, I. (2010). The paradox of communication. Socio-cognitive approach to pragmatics. Pragmatics and Society 1(1), 50-73. https://doi.org/10.1075/ps.1.1.04kec

Kecskes, I. (Ed.) (2013). Special issue: Focus on the speaker. Journal of Pragmatics, 48(1), 1-122. https://doi.org/10.1016/j.pragma.2012.11.006

Kecskes, I. (2015). Intracultural Communication and Intercultural Communication: Are They Different? International Review of Pragmatics 7(2), 171-194. https://doi.org/10.1163/ 18773109-00702002

Kecskes, I. (2018). How does intercultural communication differ from intracultural communication? In Curtis, A. \& R. Sussex (Eds.), Intercultural communication in Asia: Education, language and values (pp. 115-135). Cham: Springer.

Kecskes, I. \& Zhang, F. (2009). Activating, seeking, and creating common ground: A sociocognitive approach. Pragmatics \& Cognition 17(2), 331-355. https://doi.org/10.1075/ pc.17.2.06kec

Kita, S. (Ed.). (2003). Pointing: Where language, culture, and cognition meet. Hillsdale, NJ: Erlbaum.

Klippi, A. (2015). Pointing as embodied practice in aphasic interaction. Special Issue on Conversation and aphasia: Advances in analysis and intervention. Aphasiology, 29(3), 337-354.

Laczkó, K. (2012). Spatial deixis and demonstrative pronouns in Hungarian. In C. Hart (Ed.), Selected Papers from UK-CLA Meetings, vol. 1, 289-301. Retrieved from http://www.uk-cla. org.uk/files/proceedings/Laczko.pdf

Ledgeway, A. (2015). Varieties in Italy. In Jungbluth, K. \& F. Da Milano (Eds.), Manual of Deixis in Romance Languages (pp. 75-113). Berlin: De Gruyter.

Levinson, S.C. (1983). Pragmatics. Cambridge: Cambridge University Press.

Levinson, S.C. (1996). Language and space. Annual Review of Anthropology, 25, 353-382. https://doi.org/10.1146/annurev.anthro.25.1.353 
Levinson, S.C. (2004). Deixis. In Horn, L. \& G. Ward (Eds.), The Handbook of Pragmatics (pp. 97-121). Oxford: Blackwell.

Lyons, J. (1977). Semantics. Cambridge: Cambridge University Press.

Macagno, F. \& Bigi, S. (2017). Understanding misunderstandings. Presuppositions and presumptions in doctor-patient chronic care consultations. Intercultural Pragmatics 4(1), 49-75. 10.1515/ip-2017-0003

Marotta, G., Lenci, A., Meini, L., \& Rovai, F. (2010). Space in language. Proceedings of the Pisa International Conference. Pisa: ETS.

Merlino, S. (2018). Co-Constructing Wor(l)ds in Aphasia Speech Therapy. In Favareau, D. (Ed.), Co-operative engagements in intertwined semiosis: Essays in honour of Charles Goodwin (pp. 287-303). Tartu: University of Tartu Press.

Merlino, S. \& Mondada, L. (2019). Crossing the street: How pedestrians interact with cars. Language \& Communication, 65, 131-147. https://doi.org/10.1016/j.langcom.2018.04.004

Mihatsch, W. (2015). Cognitive Linguistics. In K. Jungbluth, \& F. Da Milano (Eds.), Manual of Deixis in Romance Languages (pp. 467-492). Berlin: De Gruyter.

Müller, C., Cienki, A.J., Fricke, E., Ladewig, S.H., McNeill, D., \& Teßendorf, S. (Eds.). (2013). Body - Language - Communication: An international handbook on multimodality in human interaction. Berlin: Mouton de Gruyter.

Mustajoki, A. (2012). A speaker-oriented multidimensional approach to risks and causes of miscommunication. Language and Dialogue 2(2), 216-243. https://doi.org/10.1075/ Id.2.2.03mus

Mustajoki, A. (2017a). Risks of miscommunication in various speech genres. In Borisova, E. \& O. Souleimanova (Eds.), Understanding by Communication (pp. 33-53). Cambridge: Cambridge Scholars Publishing.

Mustajoki, A. (2017b). Why is miscommunication more common in everyday life than in lingua franca conversation? In Kecskes, I. \& S. Assimakopoulos (Eds.), Current Issues in Intercultural Pragmatics (pp. 55-74). Amsterdam: John Benjamins.

Pietikäinen, K.S. (2016). Misunderstandings and ensuring understanding in private ELF talk. Applied Linguistics 39(2), 188-212. https://doi.org/10.1093/applin/amw005

Prandi, M. (2015). Varieties in Italy 2: Alpine Varieties. In Jungbluth, K. \& F. Da Milano (Eds.), Manual of Deixis in Romance Languages (pp. 114-139). Berlin: De Gruyter.

Schegloff, E. (1992). Repair after next turn: The last structurally provided defense of intersubjectivity in conversation. American Journal of Sociology, 97(5), 1295-1345. Retrieved from https://www.jstor.org/stable/2781417?seq=1\#metadata_info_tab_contents

Schegloff, E. A., Jefferson, G., \& Sacks, H. (1977). The Preference for Self-Correction in the Organization of Repair in Conversation. Language 53(2), 361-382. https://doi.org/ 10.1353/lan.1977.0041

Sutton, J. (2004). Representation, levels, and context in integrational linguistics and distributed cognition. Language Sciences, 26, 503-524. https://doi.org/10.1016/j. langsci.2004.09.002

Talmy, L. (2005). The fundamental system of spatial schemas in language. In Hampe, B. \& J.E. Grady (Eds.), From perception to meaning: Image schemas in cognitive linguistics (pp. 199-234). Berlin \& New York: Mouton de Gruyter.

Taylor, T. J. (1992). Mutual misunderstanding. London: Routledge.

Thomas, J. (1983). Cross-cultural pragmatic failure. Applied Linguistics 4(2), 91-112. https://doi.org/10.1093/applin/4.2.91 
Trillo, J.-R. (2011). Do you “(mis)understand” what I mean?: Pragmatic strategies to avoid cognitive maladjustment. Journal of English Studies, 9, 223-241. Retrieved from https://publicaciones.unirioja.es/ojs/index.php/jes/article/viewFile/173/153.

Trognon, A. \& Batt, M. (2018). La comunicación humana: un producto de la evolución. Cuadernos de la ALFA, 10(2), 16-28.

Varonis, E.M. \& Gass, S. (1985). Miscommunication in native/nonnative conversation. Language in Society 14(3), 327-343. https://doi.org/10.1017/S0047404500011295

Vendler, Z. (1994). Understanding misunderstanding. In Jamieson, D. (Ed.), Language, mind, and art (pp. 9-21). Dordrecht: Kluwer.

Verdonik, D. (2010). Between understanding and misunderstanding. Journal of Pragmatics 42(5), 1364-1379. https://doi.org/10.1016/j.pragma.2009.09.007

Weigand, E. (1999). Misunderstanding: The standard case. Journal of Pragmatics 31(6), 763-785. https://doi.org/10.1016/S0378-2166(98)00068-X

Zaefferer, D. (1977). Understanding misunderstanding: A proposal for an explanation of reading choices. Journal of Pragmatics 1(4), 329-346. https://doi.org/10.1016/0378-2166(77) 90027-3 